\title{
Changes in Blood Glucose Level After Steroid Injection for Musculoskeletal Pain in Patients With Diabetes
}

\author{
Woo-Yong Shin, MD, Min-Ji An, MD, Nam-Gyu Im, MD, Kyung-Rok Oh, MD, \\ Yuri Choe, MD, PhD, Seo-Ra Yoon, MD, PhD, Su-Ra Ryu, MD \\ Department of Rehabilitation Medicine, Gwangju Veterans Hospital, Gwangju, Korea
}

Objective To investigate changes in blood glucose level after steroid injection in patients with type 2 diabetes mellitus (DM) and factors affecting those changes.

Methods We retrospectively studied 51 patients with type 2 DM who underwent steroid injection for shoulder and back pain. Mean fasting blood sugar (FBS) levels for 7 days before steroid injection was used as the baseline blood glucose level, which was compared with FBS levels for 14 days after steroid injection. We compared the differences in blood glucose changes between $\mathrm{HbAlc}>7 \%$ and $\mathrm{HbAlc} \leq 7 \%$ groups and those between insulin and non-insulin treated groups. Demographic data, injection site, and steroid dose were analyzed.

Results Compared to baseline, blood glucose significantly ( $\mathrm{p}=0.012)$ elevated 1 day after steroid injection but not 2 days after injection. In the HbAlc $>7 \%$ and insulin groups, blood glucose was significantly increased 1 day after injection compared to that in the $\operatorname{HbAlc} \leq 7 \%(\mathrm{p}=0.011)$ and non-insulin $(\mathrm{p}=0.024)$ groups, respectively. Higher HbAlc level before injection was significantly ( $\mathrm{p}=0.003$ ) associated with the degree of blood glucose increase 1 day after injection. No significant differences were noted in the degree of blood glucose increase according to injection site or steroid dose.

Conclusion Higher HbAlc level was associated with greater elevation in blood glucose 1 day after steroid injection. Careful monitoring of blood glucose is required on the first day after steroid injection in patients with poorly controlled DM.

Keywords Steroid, Blood glucose, Type 2 diabetes mellitus

Received July 12, 2019; Revised August 13, 2019; Accepted September 17, 2019

Corresponding author: Yuri Choe

Department of Rehabilitation Medicine, Gwangju Veterans Hospital, 99 Cheomdanwolbong-ro, Gwangsan-gu, Gwangju 62284, Korea. Tel: +82-62-6026295, Fax: +82-62-602-6990, E-mail: drcyr@bohun.or.kr

ORCID: Woo-Yong Shin (https://orcid.org/0000-0002-6080-2617); Min-Ji An (https://orcid.org/0000-0001-6018-2529); Nam-Gyu Im (https://orcid. org/0000-0002-7200-5404); Kyung-Rok Oh (https://orcid.org/0000-0003-1989-8984); Yuri Choe (https://orcid.org/0000-0001-5712-8724); Seo-Ra Yoon (https://orcid.org/0000-0002-3694-0710); Su-Ra Ryu (https://orcid.org/0000-0002-4247-2722).

(c) This is an open-access article distributed under the terms of the Creative Commons Attribution Non-Commercial License (http://creativecommons.org/ licenses/by-nc/4.0) which permits unrestricted noncommercial use, distribution, and reproduction in any medium, provided the original work is properly cited. Copyright ( 2020 by Korean Academy of Rehabilitation Medicine 


\section{INTRODUCTION}

Steroids are being used effectively for the treatment of a variety of musculoskeletal disorders, including osteoarthritis, tendonitis, myofascial pain syndrome, and trigger fingers $[1,2]$. They are especially useful for shoulder or spinal diseases, mainly for the treatment of shoulder pain caused by rotator cuff disease or adhesive capsulitis and spinal pain caused by herniated nucleus pulposus (HNP) and spinal stenosis [1-7]. Steroids are useful for treating severe pain that requires surgical treatment in patients who cannot undergo surgery due to medical complications or other problems. However, steroid use is accompanied by various side effects such as fever, facial flushing, nausea, and fatigue. One typical side effect of steroid injection is an increase in blood glucose level [8-12].

Steroid use can inhibit the function of the hypothalamic-pituitary-adrenal (HPA) axis, rendering patients vulnerable to adrenal insufficiency and with blood glucose levels that are difficult to control $[13,14]$. It can also lower the function of glucose metabolism and stimulate gluconeogenesis, thereby increasing blood glucose level and resistance to insulin [15].

Patients with diabetes mellitus (DM) are more vulnerable to vascular injury, joint and disk disorders, and degenerative changes, and have a higher prevalence of shoulder and spinal diseases than patients without DM [16-18]. The active use of steroids in clinical practice is limited, because elevated blood glucose and associated risks are increased in patients with DM after steroid use. Recently, several studies have investigated blood glucose level elevation after steroid injection in specific areas such as wrist, finger, shoulder, and knee [10,19-24]. Although previous studies have shown blood glucose level elevation after steroid injection, the duration of blood glucose level elevation and whether blood glucose level elevation is higher in patients with poor blood glucose control, such as those with high HbAlc or taking insulin, remain controversial $[23,25,26]$.

Therefore, the aim of this study was to investigate the duration of blood glucose level elevation and the factors affecting the degree of blood glucose elevation after steroid injection in patients with type $2 \mathrm{DM}$. We hypothesized that patients with poor blood glucose control, such as patients with high HbAlc levels or those taking insulin, would have greater blood glucose level elevation.

\section{MATERIALS AND METHODS}

\section{Participants}

Between August 2017 and December 2018, we retrospectively enrolled 82 patients with type $2 \mathrm{DM}$ who had been admitted to our hospital, were using diabetes medication or insulin, and had undergone steroid injection for joint pain. This study was approved by the Institutional Review Board of Gwangju Veterans Hospital (No. 2019-21). The informed consent was waived.

The exclusion criteria were as follows: (1) patients younger than 18 years; (2) patients who had received steroid injection in the previous 3 months; (3) patients currently taking oral steroids; (4) patients with blood coagulation disorders or those in whom steroids were contraindicated or those with infections or systemic disease; (5) patients who had not monitored HbAlc level before injection or those who did not monitor blood glucose levels before or after injection.

Of the 61 patients who were not excluded, 51 patients with shoulder pain caused by adhesive capsulitis or rotator cuff disease or with back pain due to spinal stenosis or HNP were included in this study (Fig. 1). Age, sex, DM duration, body mass index (BMI), HbAlc levels during 3 months prior to injection, hypertension (HTN) presence, insulin usage, injection site, and steroid dose were investigated as factors that could affect blood glucose levels after steroid injection (Table 1).

\section{Injection protocol}

Based on medical records, patients with shoulder pain were injected with triamcinolone $20 \mathrm{mg}$ or triamcinolone $40 \mathrm{mg}$ at the subacromial subdeltoid bursa or intraarticular area according to their symptoms and lesions.

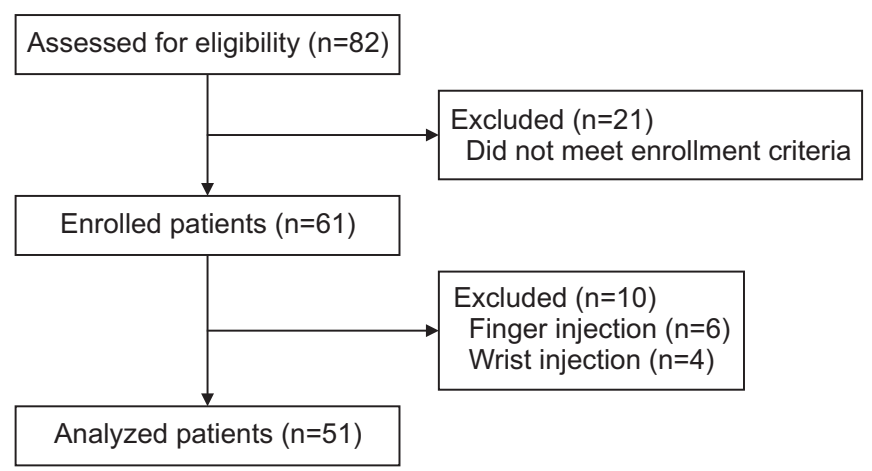

Fig. 1. Flow chart of study subjects. 
Table 1. Demographic characteristics of subjects $(n=51)$

\begin{tabular}{|cc}
\hline \multicolumn{1}{c}{ Characteristic } & Value \\
\hline Age $(\mathrm{yr})$ & $71.6 \pm 4.1$ \\
\hline DM duration $(\mathrm{yr})$ & $12.2 \pm 10.5$ \\
\hline BMI $\left(\mathrm{kg} / \mathrm{m}^{2}\right)$ & $26.0 \pm 3.5$ \\
HbAlc & $7.0 \pm 1.4$ \\
\hline $7 \%$ & $16(31.4)$ \\
$\leq 7 \%$ & $35(68.6)$ \\
\hline Sex & \\
\hline Male & $48(94.1)$ \\
\hline Female & $3(5.9)$ \\
\hline HTN & \\
\hline HTN & $47(92.1)$ \\
\hline Non-HTN & $4(7.9)$ \\
\hline Insulin use & $11(21.6)$ \\
\hline Use & $40(78.4)$ \\
\hline Not use & \\
\hline Injection site & $29(56.8)$ \\
\hline Spine & $22(43.2)$ \\
\hline Shoulder & \\
\hline Steroid dose & $4(7.8)$ \\
\hline Triam $20 \mathrm{mg}$ & $18(35.3)$ \\
\hline Triam $40 \mathrm{mg}$ & $15(29.5)$ \\
\hline Dexa $10 \mathrm{mg}$ & $14(27.4)$ \\
\hline Dexa $20 \mathrm{mg}+$ Triam $40 \mathrm{mg}$ & \\
\hline
\end{tabular}

Values area presented as mean \pm standard deviation or number (\%).

DM, diabetes mellitus; BMI, body mass index; HbAlc, hemoglobin Alc; HTN, hypertension; Triam, triamcinolone; Dexa, dexamethasone.

Patients with spine problems were treated with transforaminal epidural injection and/or medial branch blocks depending on their symptoms and lesions. They were injected with dexamethasone $10 \mathrm{mg}$ or dexamethasone 20 $\mathrm{mg}$ plus triamcinolone $40 \mathrm{mg}$. To compare the change in blood glucose according to steroid dose, triamcinolone $40 \mathrm{mg}$ and dexamethasone $7.5 \mathrm{mg}$ were studied as dose equivalent $[27,28]$.

\section{Outcome measures}

We referred to the confirmed measured HbAlc levels during the previous 3 months before steroid injection and blood glucose levels during hospitalization. The mean of fasting blood sugar (FBS) levels for 1 week prior to steroid injection was considered the baseline blood glucose level. FBS level was checked for 14 days after steroid injection and compared with baseline. Patients used existing medications and insulin as usual after steroid injection. Based on these data, we investigated whether steroid injection affected blood glucose level elevation. We categorized patients into two groups based on HbAlc $7 \%$. We also categorized patients into two groups based on whether they were being treated with insulin. We examined differences in blood glucose level changes between $\mathrm{HbAlc}>7 \%$ and $\mathrm{HbAlc} \leq 7 \%$ groups and between insulin and non-insulin groups. We also examined various factors that might have affected blood glucose levels.

\section{Statistical analysis}

Data are presented as mean \pm standard deviation. All statistical analyses were conducted using SPSS version 22.0 (IBM, Armonk, NY, USA). FBS after steroid injection over time were evaluated using repeated measures of ANOVA. We compared the degree of FBS level elevation 1 day after injection between the HbAlc $>7 \%$ and $\mathrm{HbAlc}$ $\leq 7 \%$ groups and between the insulin and non-insulin groups using the Student t-test. Multiple regression analysis was used to confirm the relationships between patient's factors and the degree of FBS level elevation 1 day after injection with respect to baseline FBS. A p-value of less than 0.05 was considered statistically significant.

\section{RESULTS}

\section{Blood glucose change after steroid injection}

FBS after steroid injection over time was statistically significant using repeated measures of ANOVA $(\mathrm{p}=0.000)$ (Fig. 2). One day after steroid injection in all the patients, blood glucose levels had significantly increased by $64.0 \pm 29.4 \mathrm{mg} / \mathrm{dL}$ compared with baseline blood glucose $(\mathrm{p}=0.012)$. However, at 2 days after injection, blood glucose levels reverted to baseline levels, showing no significant increase with respect to the baseline blood glucose levels ( $\mathrm{p}=0.333$ ) (Fig. 2).

\section{Factors affecting blood glucose elevation}

Blood glucose level was significantly elevated 1 day after steroid injection compared to baseline blood glucose, but not 2 days after injection, so we analyzed the relationships between the degree of blood glucose increase 1 day after steroid injection and the various factors. 
Both HbAlc $>7 \%(p=0.019)$ and HbAlc $\leq 7 \%(p=0.027)$ groups had a statistically significant increase in blood glucose 1 day after steroid injection. There was also a significant difference in the increase in blood glucose level between the two groups $(p=0.011)$. In the HbAlc $>7 \%$ group, blood glucose level was increased by $99.4 \pm 30.7$

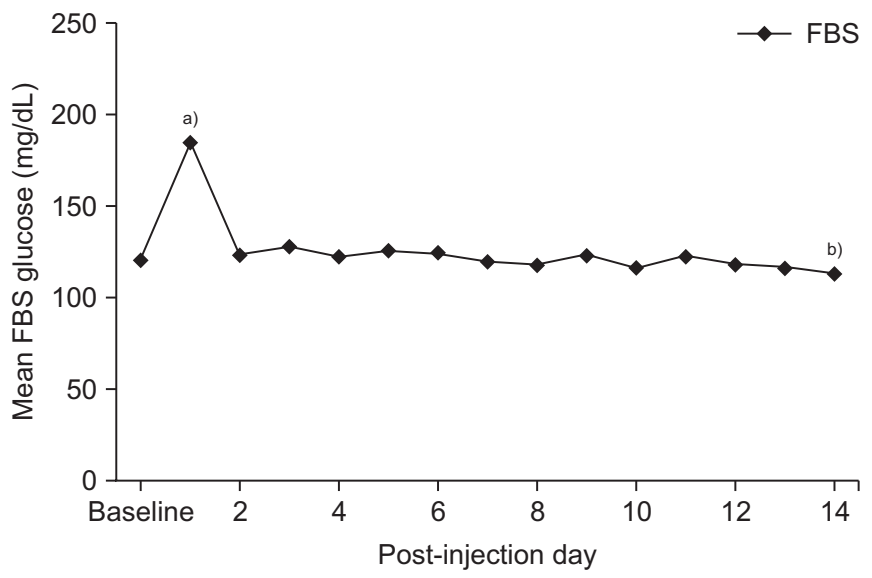

Fig. 2. Total average fasting blood sugar after injection. This figures shows mean fasting blood sugar (FBS) level was significantly elevated at 1 day after steroid injection compared to baseline FBS, but not significantly increased

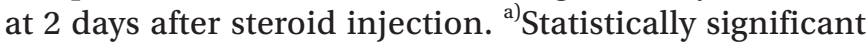
$(p=0.012)$ in comparison between baseline and after 1 day. ${ }^{\text {b) }}$ Statistically significant $(\mathrm{p}=0.000)$ in fasting blood glucose after steroid injection over time using repeated measures of ANOVA.

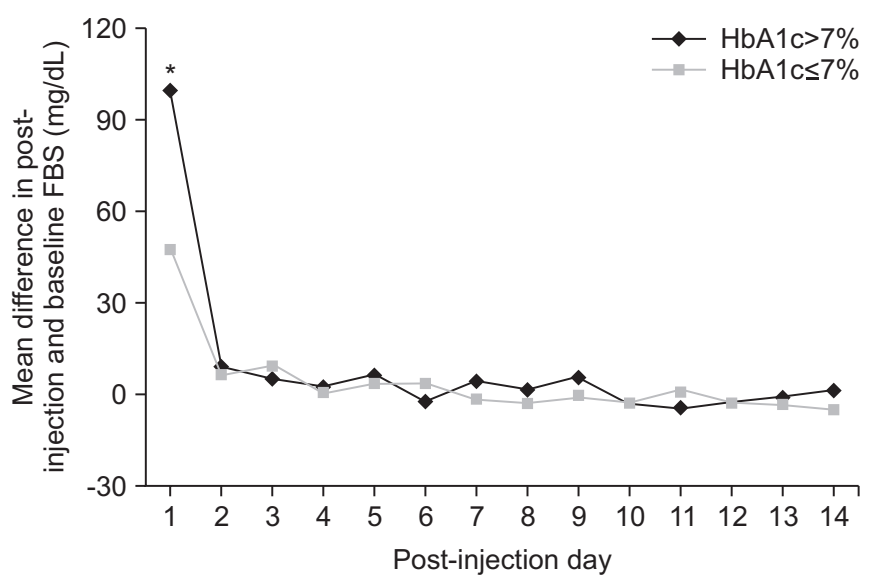

Fig. 3. Change in fasting blood sugar (FBS) level after injection in the HbAlc $>7 \%$ group versus the HbAlc $\leq 7 \%$ group. This figure show the HbAlc $>7 \%$ group had a significantly higher degree of FBS increase 1 day after steroid injection than did the HbAlc $\leq 7 \%$ group. ${ }^{*} \mathrm{p}<0.05$. $\mathrm{mg} / \mathrm{dL}$ with respect to baseline. In the $\mathrm{HbAlc} \leq 7 \%$ group, blood glucose was increased by $47.6 \pm 10.1 \mathrm{mg} / \mathrm{dL}$ with respect to baseline. However, there was no significant difference in the decrease in blood glucose levels between the two groups because blood glucose levels had declined to baseline 2 days after steroid injection $(\mathrm{p}=0.142)$ (Fig. 3).

Both the insulin group $(\mathrm{p}=0.022)$ and non-insulin group $(p=0.035)$ showed a statistically significant increase in blood glucose levels 1 day after steroid injection. A significant difference in the increase in blood glucose levels was observed between the two groups $(p=0.024)$. In the insulin group, blood glucose level was increased by $134.5 \pm 37.6 \mathrm{mg} / \mathrm{dL}$ with respect to baseline. In the noninsulin group, blood glucose was increased by $56.2 \pm 19.2$ $\mathrm{mg} / \mathrm{dL}$ with respect to baseline. However, no significant difference in decrease in blood glucose level was observed between the two groups because blood glucose levels had declined to baseline 2 days after steroid injection ( $\mathrm{p}=0.213$ ) (Fig. 4).

Among various factors, we found that the higher the HbAlc level before injection, the more significant the blood glucose increase after injection $(\mathrm{r}=0.419, \mathrm{p}=0.003)$. However, multiple regression analysis revealed that age, sex, DM duration, BMI, HTN presence, insulin use, injection site, or steroid dose did not significantly affect blood glucose after steroid injection ( $p>0.05$ ) (Table 2).

During the study, side effects, such as diabetic ketoaci-

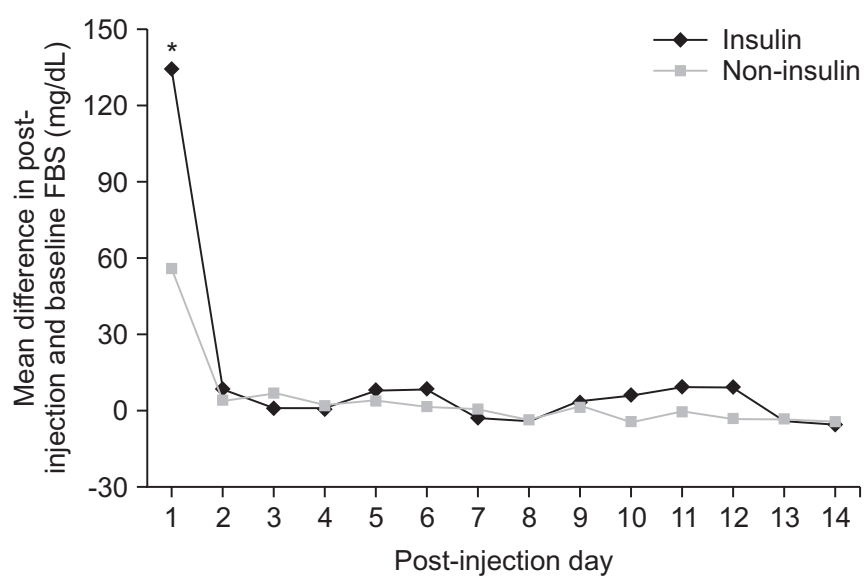

Fig. 4. Change in fasting blood sugar (FBS) level after injection in the insulin group versus the non-insulin group. This figure shows that the insulin group had a significantly higher degree of FBS increase 1 day after steroid injection than did the non-insulin group. ${ }^{*} \mathrm{p}<0.05$. 
Table 2. Relation between patient's factor and degree of FBS level elevation one day after injection with respect to baseline FBS

\begin{tabular}{lcccc}
\hline \multicolumn{1}{c}{ Variable } & $\boldsymbol{\beta}$ & $\mathbf{r}$ & $\mathbf{p}$-value & $\mathbf{R}^{2}$ \\
\hline Age & 0.032 & 0.091 & 0.790 & 0.580 \\
DM duration & 0.178 & 0.112 & 0.156 & \\
BMI & -0.095 & -0.230 & 0.373 & \\
HbAlc & 0.473 & 0.419 & $0.003^{* *}$ & \\
Sex & 0.104 & - & 0.154 & \\
HTN & 0.102 & - & 0.352 & \\
Insulin use & 0.178 & - & 0.276 & \\
Injection site & 0.089 & - & 0.453 & \\
Dose of steroid & 0.098 & - & 0.373 & \\
\hline
\end{tabular}

FBS, fasting blood sugar; HTN, hypertension; DM, diabetes mellitus; BMI, body mass index; HbAlc, hemoglobin Alc. ${ }^{* *} \mathrm{p}<0.01$.

dosis or hyperosmolar nonketotic coma as hyperglycemic complications resulting from steroid injection, were not observed.

\section{DISCUSSION}

The aim of this study was to investigate the duration of blood glucose level elevation after steroid injection in patients with type $2 \mathrm{DM}$ and whether associated factors and poor blood glucose control play a role in the elevation of blood glucose levels. A total of 82 patients were retrospectively reviewed. Of 61 patients who met the inclusion criteria, 51 patients who had received steroid injections in the shoulder or spine were enrolled in this study. Patients with steroid injection in the shoulder or spine were enrolled because we assume the effect of the injection on blood glucose levels can be more precisely studied when the injection is administered to a large joint. Conversely, we considered that small joints, such as the wrist and those of the fingers, are usually injected with small volumes of steroid, making it difficult to precisely examine any side effects of the injected steroid [29].

After steroid injection, blood glucose levels were significantly elevated for 1 day but decreased to baseline levels after 2 days. Clinically, HbAlc levels have been reported to be significant in terms of glycemic control for the previous 3 months and response to DM treatment $[19,30]$. Commonly, patients with HbAlc levels exceeding $6.5 \%$ are diagnosed with DM. Previous studies have recommended that HbAlc levels be maintained below 7\%, because the risk of various complications due to DM are increased if HbAlc levels exceed 7\% [31]. Therefore, we categorized participants into two groups based on HbAlc $(\leq 7 \%$ or $>7 \%$ ). Participants were also categorized into two groups according to insulin treatment. Blood glucose levels were more significantly increased one day after steroid injection in the HbAlc $>7 \%$ and insulin groups, than in the HbAlc $\leq 7 \%$ and non-insulin groups, respectively, which is congruous with the results of Aleem et al. [22]. When patients were compared on the basis of HbAlc $6.5 \%$, no significant differences were noted between the two groups in the degree of blood glucose level elevation 1 day after steroid injection. A few previous studies on the differences in blood glucose levels between the two groups according to HbAlC 7\% level and insulin were identified, but no study has reported whether HbAlc levels or insulin dependence are associated with blood glucose level elevation. In this study, multiple regression analysis showed that HbAlc level was associated with blood glucose level elevation, whereas insulin use was not associated with such elevation. Because multiple regression analysis includes the effects between factors, it is a more meaningful method in analyzing the factors that may affect blood glucose elevation. This indicates that the degree of usual blood glucose control rather than insulin dependence is related to blood glucose level elevation after steroid injection.

Several studies have investigated blood glucose level changes after steroid injection. Wang and Hutchinson [20] reported that after injecting $10 \mathrm{mg}$ of methylprednisolone into the trigger finger of 18 patients, blood glucose level was significantly increased for 1 day after injection but 
returned to the baseline level on the second day. Stepan et al. [10] have reported that after 20-120 mg of methylprednisolone was injected into the hand and wrist of 40 patients, blood glucose level was significantly elevated for 2 days after injection but returned to baseline on the third day. These results are consistent with our results, showing that blood glucose levels were significantly elevated for 1 day after steroid injection but returned to baseline after 2 days, and showed no significant increase with respect to the baseline level. After steroid injection, extrinsic steroids inhibit the function of the HPA axis, rendering patients vulnerable to adrenal insufficiency and with blood glucose levels that are difficult to control $[13,14]$. Other studies have shown that more doses of steroids increase the risk and duration of blood glucose elevation, which has led to changes in existing diabetes treatments $[26,32,33]$. These results differ from those of our study, which showed a significant increase in blood glucose for 1 day after steroid injection. Because only a single and limited dose of steroid was injection in our study, it is possible that the steroid dose used in our study did not have a significant effect on HPA axis inhibition seen in patients with diabetes.

Choudhry et al. [34] performed a systematic review of literature related to steroid injection in DM patients. They reported that patients exhibited elevation of up to $500 \mathrm{mg} / \mathrm{dL}$ in blood glucose levels after steroid injection. However, no patients had severe complications such as diabetic ketoacidosis or hyperosmolar nonketotic coma. The results of their study were consistent with those of our study in which diabetic ketoacidosis or hyperosmolar nonketotic coma were not observed, although 5 patients exhibited elevation of up to $350 \mathrm{mg} / \mathrm{dL}$ in blood glucose levels with respect to the baseline glucose levels, after steroid injection.

This study has some limitations. First, although it was a retrospective study, the sample size was relatively small. However, it is a retrospective study based on blood glucose records. Therefore, blood glucose results were accurate. In previous prospective studies that were not based on medical records, recall bias may have been present, because patients' measured blood glucose results and data collection were based on patient memory. Second, as all the patients had type $2 \mathrm{DM}$, there were no comparisons made between type $1 \mathrm{DM}$ and type $2 \mathrm{DM}$ or between non-DM and type 2 DM. Third, most patients were over
60 years old and male. Thus, we were unable to fully control the variables. Fourth, we did not study the effects of common diabetic complications, such as chronic kidney disease, retinopathy, and sarcopenia, on blood glucose level elevation. Future studies considering these aspects are required. Fifth, although particle steroids may have a longer tissue effect duration, which may affect glucose metabolism, we did not study the changes in blood glucose that may be caused by particle differences between dexamethasone and triamcinolone. Sixth, we did not examine whether steroid injection has long-term effects on blood glucose level elevation. HbAlc levels have been reported to be significant in terms of the status of glycemic control for 3 months $[19,30]$. Therefore, HbAlc is a reliable method to understand the effect on long-term blood glucose control after steroid injection. However, because it was a retrospective study, we could not periodically assess HbAlc after steroid injection nor could we control for re-injection or changes in diabetes treatment modality after steroid injection.

Active steroid use in patients with type $2 \mathrm{DM}$ has been challenging because the duration for which blood glucose levels remain elevated is unclear. However, this study showed that blood glucose levels increased for up to 1 day after steroid injection and returned to the baseline level on the second day. Among various factors, HbAlc level affected the extent of increase in blood glucose levels. Patients who had poor usual blood glucose control had higher blood glucose levels after steroid injection. Based on results of this study, steroid injection in should be administered more carefully in patients with higher HbAlc levels. As blood glucose levels increase for up to 1 day after steroid injection, steroids can be safely used if blood glucose levels are regularly monitored and managed during this transient elevation period.

\section{CONFLICT OF INTEREST}

No potential conflict of interest relevant to this article was reported.

\section{AUTHOR CONTRIBUTION}

Conceptualization: Shin WY, Choe YR. Methodology: Shin WY, An MJ, Im NG, Oh KR, Choe YR, Yoon SR, Ryu SR. Formal analysis: Shin WY, Choe YR. Project admin- 
istration: Shin WY, An MJ, Im NG, Oh KR, Choe YR, Yoon SR, Ryu SR. Visualization: Shin WY, Choe YR. Writing original draft: Shin WY, Choe YR. Writing - review and editing: Shin WY, An MJ, Im NG, Oh KR, Choe YR, Yoon SR, Ryu SR. Approval of final manuscript: all authors.

\section{REFERENCES}

1. Arslan S, Celiker R. Comparison of the efficacy of local corticosteroid injection and physical therapy for the treatment of adhesive capsulitis. Rheumatol Int 2001;21:20-3.

2. Lorbach O, Kieb M, Scherf C, Seil R, Kohn D, Pape D. Good results after fluoroscopic-guided intra-articular injections in the treatment of adhesive capsulitis of the shoulder. Knee Surg Sports Traumatol Arthrosc 2010;18:1435-41.

3. Botwin KP, Gruber RD, Bouchlas CG, Torres-Ramos FM, Sanelli JT, Freeman ED, et al. Fluoroscopically guided lumbar transformational epidural steroid injections in degenerative lumbar stenosis: an outcome study. Am J Phys Med Rehabil 2002;81:898-905.

4. Ranalletta M, Rossi LA, Bongiovanni SL, Tanoira I, Elizondo CM, Maignon GD. Corticosteroid injections accelerate pain relief and recovery of function compared with oral NSAIDs in patients with adhesive capsulitis: a randomized controlled trial. Am J Sports Med 2016;44:474-81.

5. Buttermann GR. The effect of spinal steroid injections for degenerative disc disease. Spine J 2004;4:495-505.

6. Zufferey P, Revaz S, Degailler X, Balague F, So A. A controlled trial of the benefits of ultrasound-guided steroid injection for shoulder pain. Joint Bone Spine 2012;79:166-9.

7. Chen MJ, Lew HL, Hsu TC, Tsai WC, Lin WC, Tang SF, et al. Ultrasound-guided shoulder injections in the treatment of subacromial bursitis. Am J Phys Med Rehabil 2006;85:31-5.

8. Hart L. Corticosteroid and other injections in the management of tendinopathies: a review. Clin J Sport Med 2011;21:540-1.

9. Habib GS, Miari W. The effect of intra-articular triamcinolone preparations on blood glucose levels in diabetic patients: a controlled study. J Clin Rheumatol 2011;17:302-5.

10. Stepan JG, London DA, Boyer MI, Calfee RP. Blood glucose levels in diabetic patients following corticosteroid injections into the hand and wrist. J Hand Surg Am 2014;39:706-12.

11. Even JL, Crosby CG, Song Y, McGirt MJ, Devin CJ. Effects of epidural steroid injections on blood glucose levels in patients with diabetes mellitus. Spine (Phila Pa 1976) 2012;37:E46-50.

12. Botwin KP, Gruber RD, Bouchlas CG, Torres-Ramos FM, Freeman TL, Slaten WK. Complications of fluoroscopically guided transforaminal lumbar epidural injections. Arch Phys Med Rehabil 2000;81:1045-50.

13. Donatti TL, Koch VH, Takayama L, Pereira RM. Effects of glucocorticoids on growth and bone mineralization. J Pediatr (Rio J) 2011;87:4-12.

14. Duclos M, Guinot M, Colsy M, Merle F, Baudot C, Corcuff JB, et al. High risk of adrenal insufficiency after a single articular steroid injection in athletes. Med Sci Sports Exerc 2007;39:1036-43.

15. Iwamoto T, Kagawa Y, Naito Y, Kuzuhara S, Kojima M. Steroid-induced diabetes mellitus and related risk factors in patients with neurologic diseases. Pharmacotherapy 2004;24:508-14.

16. Lotan R, Oron A, Anekstein Y, Shalmon E, Mirovsky Y. Lumbar stenosis and systemic diseases: is there any relevance? J Spinal Disord Tech 2008;21:247-51.

17. Jeffcoate WJ, Game F, Cavanagh PR. The role of proinflammatory cytokines in the cause of neuropathic osteoarthropathy (acute Charcot foot) in diabetes. Lancet 2005;366:2058-61.

18. Xu G, Pierson CR, Murakawa Y, Sima AA. Altered tubulin and neurofilament expression and impaired axonal growth in diabetic nerve regeneration. J Neuropathol Exp Neurol 2002;61:164-75.

19. Kim N, Schroeder J, Hoffler CE, Matzon JL, Lutsky KF, Beredjiklian PK. Elevated hemoglobin AlC levels correlate with blood glucose elevation in diabetic patients following local corticosteroid injection in the hand: a prospective study. Plast Reconstr Surg 2015;136:474e-9e.

20. Wang AA, Hutchinson DT. The effect of corticosteroid injection for trigger finger on blood glucose level in diabetic patients. J Hand Surg Am 2006;31:979-81.

21. Yoon JS, Kim SJ, Park EM. The change of blood sugar level after steroid injection in shoulder pain with diabetes mellitus. J Korean Acad Rehabil Med 2003;27:557-60. 
22. Aleem AW, Syed UA, Nicholson T, Getz CL, Namdari S, Beredjiklian PK, et al. Blood glucose levels in diabetic patients following corticosteroid injections into the subacromial space of the shoulder. Arch Bone Jt Surg 2017;5:315-21.

23. Habib G, Safia A. The effect of intra-articular injection of betamethasone acetate/betamethasone sodium phosphate on blood glucose levels in controlled diabetic patients with symptomatic osteoarthritis of the knee. Clin Rheumatol 2009;28:85-7.

24. Kallock E, Neher JO, Safranek S. Clinical inquiries. Do intra-articular steroid injections affect glycemic control in patients with diabetes? J Fam Pract 2010;59:70910.

25. Moon HJ, Choi KH, Lee SI, Lee OJ, Shin JW, Kim TW. Changes in blood glucose and cortisol levels after epidural or shoulder intra-articular glucocorticoid injections in diabetic or nondiabetic patients. Am J Phys Med Rehabil 2014;93:372-8.

26. Kim WH, Sim WS, Shin BS, Lee CJ, Jin HS, Lee JY, et al. Effects of two different doses of epidural steroid on blood glucose levels and pain control in patients with diabetes mellitus. Pain Physician 2013;16:557-68.

27. Dahl J, Hammert WC. Overview of injectable corticosteroids. J Hand Surg Am 2012;37:1715-7.

28. MacMahon PJ, Eustace SJ, Kavanagh EC. Injectable corticosteroid and local anesthetic preparations: a re- view for radiologists. Radiology 2009;252:647-61.

29. Catalano LW 3rd, Glickel SZ, Barron OA, Harrison R, Marshall A, Purcelli-Lafer M. Effect of local corticosteroid injection of the hand and wrist on blood glucose in patients with diabetes mellitus. Orthopedics 2012;35:e1754-8.

30. Stratton IM, Adler AI, Neil HA, Matthews DR, Manley SE, Cull CA, et al. Association of glycaemia with macrovascular and microvascular complications of type 2 diabetes (UKPDS 35): prospective observational study. BMJ 2000;321:405-12.

31. Ahmed N. Advanced glycation endproducts: role in pathology of diabetic complications. Diabetes Res Clin Pract 2005;67:3-21.

32. Morris D. Steroid-induced diabetes and hyperglycaemia. Part 1: Mechanisms and risks. Diabetes Prim Care 2018;20:151-3.

33. Younes M, Neffati F, Touzi M, Hassen-Zrour S, Fendri Y, Bejia I, et al. Systemic effects of epidural and intraarticular glucocorticoid injections in diabetic and non-diabetic patients. Joint Bone Spine 2007;74:4726.

34. Choudhry MN, Malik RA, Charalambous CP. Blood glucose levels following intra-articular steroid injections in patients with diabetes: a systematic review. JBJS Rev 2016;4:01874474-201603000-00002. 